\title{
PRINCIPAIS ASSUNTOS DE AUDITORIA: EXPECTATIVAS DOS AUDITORES INDEPENDENTES QUANTO AO NOVO RELATÓRIO DE AUDITORIA
}

\section{KEY AUDIT MATTERS:" INDEPENDENT AUDITORS EXPECTATIONS REGARDING THE NEW AUDIT REPORT}

\author{
0 artigo foi aprovado e apresentado no XIV Online Conference - Administração 2017, realizado de 28/11 a 2/12 de 2017, em Ambiente Virtual.
}

\begin{abstract}
RESUMO
Diante da recente divulgação da NBC TA 701 que trata sobre os principais assuntos de auditoria, o presente estudo teve como objetivo analisar quais as expectativas dos auditores independentes quanto ao novo relatório de auditoria independente (NRA) e os efeitos no planejamento e honorários do serviço. Foi realizada uma pesquisa descritiva e exploratória, com procedimentos bibliográficos e de campo com abordagem qualitativa. Para alcançar o objetivo foi aplicado um questionário para 63 auditores independentes com maior tempo de experiência no mercado e com cargos em nível de planejamento de auditoria. Os profissionais relataram sobre o planejamento e honorários de auditoria, indicando provável aumento quando há alta complexidade dos negócios, maior porte do cliente, quando é realizada a primeira auditoria e quando o cliente é vinculado a agências reguladoras. Por outro lado, entendem que uma empresa com melhores práticas de governança provavelmente terá menores custos com remuneração dos auditores, pois há previsão de menores riscos do negócio. Quanto aos efeitos dos principais assuntos de auditoria no planejamento e honorários, verificou-se que a percepção geral é que a maioria entende que não haverá efeitos relevantes nos honorários de auditoria. Por outro lado, a maioria também entende que terão efeitos no planejamento de auditoria devido principalmente a participação de auditores seniores ou sócios nas discussões com a empresa auditada. Há também o entendimento de que a identificação de riscos do cliente e os efeitos disso na execução de auditoria já eram procedimentos realizados, e que a divulgação disso no relatório de auditoria não acarretaria em grandes efeitos no planejamento da auditoria.
\end{abstract}

Palavras-chave: Auditoria independente; Principais Assuntos de Auditoria; NBC TA 701.

\begin{abstract}
In light of the recent disclosure of ISA 701 which addresses the key audit matters, this study aimed to analyze the expectations of independent auditors regarding the New Independent Audit Report (NIAR) and the effects on service planning and fees. A descriptive and exploratory research was carried out with bibliographic and field procedures with a qualitative approach. In order to reach the objective, a questionnaire was applied to 63 independent auditors with a greater market experience and audit planning positions. Professionals reported on audit planning and fees, indicating a probable increase when there is a high business complexity, greater size client, when the first audit is performed and when the client is linked to regulatory agencies. On the other hand, they understand that a company with better governance practices will probably have lower costs with auditor remuneration, since there is a lower business risk forecast. As for key audit matters effects on planning and fees, the general perception found is that there will be no relevant effects on audit fees. However, the majority also understands that there will be effects on audit planning mainly due to the participation of senior auditors or partners in the discussions with the audited company. There is also the understanding that the identification of client risks and the effects thereof in the audit execution were already performed procedures and that its disclosure in the audit report would not have major effects on audit planning.
\end{abstract}

Keywords: Independent Auditing; Key Audit Matters; NBC TA 701

\begin{abstract}
Ana Carolina Vasconcelos Colares Doutoranda e Mestre em Controladoria e Contabilidade pela Universidade Federal de Minas Gerais (UFMG). Especialista em Gestão Ambiental de Empresas (AVM). Graduada em Ciências Contábeis pela Universidade Federal do Ceará e em Administração pela Pontifícia Universidade Católica de Minas Gerais (PUC Minas). Docente do Curso de Ciências Contábeis pela Pontifícia Universidade Católica de Minas Gerais (PUC Minas). Contato: Rua Walter lanni, 225 - São Gabriel - Belo Horizonte - MG. CEP: 31980-110.

E-mail: carolinacolares@pucminas.br.
\end{abstract}

\section{Izabelle Karoline Cruz Alves}

Especialista em Controladoria pelo Instituto Brasileiro de Mercado de Capitais (IBMEC). Graduada em Ciências Contábeis com Ênfase em Controladoria pela Pontifícia Universidade Católica de Minas Gerais (PUC Minas). Contato: Rua Everest, 26 - Belmonte - Belo Horizonte - MG, CEP: 31.990-380. E-mail: izabellekca@hotmail.com

\section{Cássia Oliveira Ferreira}

Mestranda em Controladoria e Contabilidade pela Universidade Federal de Minas Gerais (UFMG). Especialista em Gestão Estratégica em Finanças Empresariais pela Universidade Federal de Minas Gerais (UFMG). Graduada em Ciências Contábeis Ênfase em Controladoria pela Pontifícia Universidade Católica de Minas Gerais (PUC Minas). Contato: Rua Miguel Gomes da Costa, 298, Mantiqueira, Belo Horizonte, MG, CEP: 31652-320. E-mail: cassia.oliveiraf@hotmail.com. 


\section{INTRODUÇÃO}

O serviço prestado pela auditoria independente é fundamental para maior transparência e confiabilidade dos relatórios financeiros das empresas de capital aberto. As possíveis ameaças à independência e qualidade das suas análises, os custos dos serviços e a relação com os mecanismos de governança corporativa (GC) são temas explorados internacionalmente (BORTOLON, SARLONETO, SANTOS, 2013).

A partir do relatório de auditoria, os stakeholders do mercado financeiro buscam asseguração em relação as demonstrações financeiras analisadas, depositando assim, no trabalho de auditoria, a expectativa acerca da confiabilidade dos resultados apresentados pelas entidades. O trabalho do auditor independente é visto como necessário para validar as informações contidas nas demonstrações contábeis, auxiliando na tomada de decisões por parte dos stakeholders. Tendo em vista a importância da auditoria, se torna necessário que as demonstrações das entidades brasileiras proporcionem entendimento e comparabilidade no mundo todo, bem como transmitam a segurança de que as demonstrações foram auditadas conforme as melhores práticas internacionais de auditoria (LONGO, 2011).

Alguns estudos têm buscado analisar a qualidade da auditoria independente e os resultados da sua ausência, sendo esta uma discussão importante, principalmente para introduzir normas de auditoria que possibilitem maior qualidade do serviço. Silva e Silva (2014) investigaram a qualidade da auditoria independente realizada em empresas com grandes perdas com instrumentos financeiros derivativos. Os resultados revelaram um indício de baixa qualidade das auditorias realizadas, ao se notar que apesar de a companhia receber um parecer de auditoria sem ressalvas sobre as Demonstrações Financeiras e Informações Trimestrais, houve perdas significativas com instrumentos financeiros derivativos cuja exposição aos riscos não foi evidenciada.

Santos et al. (2013) buscaram responder se os Analistas Financeiros tendem a subestimar a importância do trabalho do auditor para obter informações financeiras confiáveis ou os Analistas de Mercado julgam que os auditores não são eficazes na identificação de erros e fraudes relevantes para as demonstrações financeiras. Os resultados evidenciaram que a confiabilidade e a imagem do auditor, perante os analistas financeiros, encontram-se abalada.

De acordo com o Financial Reporting Council (FRC) (2015) a crise financeira de 2008, deu impulso às alterações nas normas contábeis no que diz respeito ao relatório de auditoria independente, tendo em vista que as normas vigentes não forneciam confiabilidade suficiente para auxiliar o processo de tomada de decisão por parte dos stakeholders no mercado financeiro. Desta forma, em 2011, houve a alteração no relatório de auditoria independente a fim de proporcionar maior segurança aos usuários. Em 2015, o International Federation of Accountants (IFAC) iniciou o processo de revisão das normas internacionais de contabilidade que regem o relatório de auditoria independente, visando a adoção do Novo Relatório de Auditoria (NRA).

No Brasil, estas alterações aconteceram em 2016 após a tradução das Internacional Standards on Auditing (ISAs) e diversos debates com demais órgãos reguladores e audiências públicas, introduzindo, após a aprovação destas alterações das Normas Brasileiras de Contabilidade Técnicas de Auditoria (NBC TAs) o Novo Relatório de Auditoria. Para que as mudanças que a contabilidade no Brasil vem adotando possam ocorrer da melhor maneira possível, diminuindo as dificuldades enfrentadas nesse processo, deve ser avaliada a forma como essa mudança vem sendo introduzida e abordada, identificadas as dificuldades e analisado o ponto de vista dos envolvidos, tornando possível traçar um caminho exitoso, alcançando os objetivos pretendidos com a adoção das normas internacionais de auditoria. Nesse contexto atual, se destaca a NBC TA 701 que dispõe sobre a comunicação dos principais assuntos de auditoria no relatório do auditor independente, datada em julho de 2016 tendo correlação com a International Standard on Auditing 701 (ISA 701). Por ser uma norma recente, a qual passou a ser exigida somente após o encerramento do exercício de 2016, gera ainda incertezas quanto à sua aplicabilidade. As firmas de auditoria devem se capacitar para as novas mudanças, bem como as empresas auditadas que ficarão mais expostas por meio da divulgação dos principais assuntos de auditoria e outros elementos do novo relatório de auditoria. De acordo com a NBC TA 701, a quantidade de principais assuntos de auditoria a serem incluídos no relatório do auditor pode ser impactada pelo porte e complexidade da entidade, natureza de seus negócios e ambiente, bem como fatos e circunstâncias do trabalho de auditoria.

Dentre as expectativas referentes à norma, Backof, Bowlin e Goodson (2017) entendem que as mudanças propostas no relatório de auditoria afetam a tomada de decisão do usuário e a capacidade da auditoria de defender seu trabalho. Manoel e Quel (2017) acreditam que o novo relatório traz benefícios importantes. Ele é uma resposta as expectativas dos usuários, já que comunicam informações mais detalhadas relacionadas à auditoria realizada. Prasad e Chand (2017) acreditam que as mudanças aumentarão os custos de auditoria e, dessa forma, a responsabilidade legal dos auditores. Esta avaliação é coerente, levando em consideração os esforços feitos pelo International Accounting Standards Board (IASB) no comissionamento dessas mudanças para melhorar a relevância e o valor informativo do relatório de auditoria.

Com base nessa discussão, a presente pesquisa propõe analisar quais as expectativas dos auditores independentes quanto ao novo relatório de auditoria independente (NRA) e os efeitos no planejamento e honorários do serviço. Esta pesquisa torna-se relevante tendo em vista que as recentes mudanças nas normas de auditoria terão impactos diretos na forma dos relatórios de auditoria independente, tendo maiores poderes de influenciar a tomada de decisão de seus usuários, uma vez que a profundidade nos relatos expõe as deficiências internas das empresas auditadas, os riscos de distorção relevante, além da própria qualidade de suas informações contábeis divulgadas. Mesmo no contexto internacional, o qual a norma foi discutida pelo International Federation of Accountants (IFAC) e aplicada aos 
relatórios financeiros no exercício de 2014 e 2015 no Reino Unido, por exemplo, ainda se trata de uma temática pouco explorada nos periódicos acadêmicos da área.

\section{REFERENCIAL TEÓRICO}

\subsection{Normas Internacionais de Contabilidade e de Auditoria no Brasil}

Como consequência às mudanças no contexto internacional, o Brasil iniciou suas mudanças através de publicações, com a Comissão de Valores Mobiliários (CVM) pela Instrução Normativa n 457/07, o Banco Central pelo Comunicado $n^{\circ} 14.259 / 06$ e a SUSEP pela Circular $n^{\circ} 357 / 07$, sendo instituído que a partir de 2010, as instituições financeiras em geral, as empresas abertas e as seguradoras deveriam preparar as demonstrações financeiras consolidadas de acordo com as Normas Internacionais de Contabilidade (ATTIE, 2011). O Brasil implementou as novas normas internacionais aprovadas pelo projeto Clarity da IFAC com vigência a partir de 2010 quase que simultaneamente a aprovação e vigência Internacional. Para viabilizar o atendimento a esse compromisso assumido, foi criado o Comitê Gestor da Convergência no Brasil. Segundo Longo (2011, p. 5), "esse comitê foi constituído com o objetivo de contribuir para o desenvolvimento sustentável do Brasil por meio da reforma contábil e de auditoria que resulte em maior transparência e aprimoramento das práticas profissionais".

O Brasil é um país que desperta interesse econômico no mercado internacional, atualmente existe um grande número de empresas multinacionais estrangeiras instaladas no Brasil, bem como empresas brasileiras instaladas no exterior, portanto a internacionalização das normas vem para diminuir as dificuldades até então enfrentadas nessas relações e incentivar a criação de novas.

Assim como para a contabilidade também foram adotadas novas normas de auditoria (NBC TAs), essas normas entraram em vigor para trabalhos de auditoria de demonstrações financeiras, de exercícios a partir de janeiro de 2010. As normas de auditoria se relacionam com as medidas de qualidade da execução das ações a serem efetuadas e dos objetivos a serem alcançados através dos procedimentos. As práticas contábeis brasileiras começaram a sofrer modificações através da Lei $n^{\circ} 11.638 / 07$, atualmente estão em vigor as NBCs, descritas em forma de Resoluções do Conselho Federal de Contabilidade (CFC).

Diante desse contexto das normas de auditoria, surgiu o Novo Relatório do Auditor (NRA) que é composto por normas que haviam sido alteradas durante processo de revisão das ISAs, realizado pela IFAC em 2015. As seis normas publicadas são: NBC TA 260 (R2) - Comunicação com os Responsáveis pela Governança; NBC TA 570 Continuidade Operacional; NBC TA 700 - Formação da Opinião e Emissão do Relatório do Auditor Independente sobre as Demonstrações Contábeis; NBC TA 701 - Comunicação dos Principais Assuntos de Auditoria no Relatório do Auditor Independente; NBC TA 705 - Modificações na Opinião do Auditor Independente; e NBC TA 706 - Parágrafos de Ênfase e Parágrafos de Outros Assuntos no Relatório do Auditor Independente (CONSELHO FEDERAL DE CONTABILIDADE, 2016).

O NRA é constituído por normas convergidas das International Standards on Auditing (ISAs), emitidas pela Federação Internacional de Contabilidade (IFAC). Após a tradução das ISAs, feita pelo CFC e pelo Instituto dos Auditores Independentes do Brasil (IBRACON), as minutas passaram por audiência pública no site do CFC. O processo de avaliação das sugestões recebidas na audiência foi realizado pela Câmara Técnica e, na reunião plenária do dia 17 de junho, os conselheiros aprovaram as seis NBCs. O NRA responde a uma necessidade de maior transparência nas informações emitidas ao mercado, pois os investidores e outros usuários serão beneficiados com dados que antes não eram de conhecimento público (CONSELHO FEDERAL DE CONTABILIDADE, 2016).

\subsection{Novo Relatório do Auditor Independente}

O novo relatório do auditor foi exposto ao público pelo Conselho Federal de Contabilidade que tratou da alteração da norma de auditoria NBC TA 700 com a inclusão da NBC TA 701 e a alteração de outras que com elas interagem, sobre Formação da Opinião e Emissão do Relatório do Auditor Independente sobre as Demonstrações Contábeis (ACADEMIA PAULISTA DE CONTABILIDADE, 2016)

A partir do encerramento das demonstrações financeiras de 31/12/2016, o relatório do auditor independente sofrerá grandes mudanças em relação à sua apresentação. O auditor contábil recebe uma responsabilidade ainda maior, de expressar no relatório do auditor independente uma abordagem mais informativa e inteligível para os leitores do relatório (BLB BRASIL, 2016).

Sem alterar o escopo de uma auditoria independente, o auditor irá fornecer aos usuários mais transparência sobre os seus afazeres, as suas responsabilidades e as responsabilidades da Administração e, para entidades listadas, mais compreensão sobre os principais assuntos da auditoria. Ao explicar como os assuntos de auditoria foram conduzidos, o novo relatório do auditor vai ajudar a melhorar a natureza da comunicação com as partes interessadas e permitir que os usuários reconheçam o valor da auditoria (KPMG AUDITORES INDEPENDENTES, 2016).

De acordo com o novo modelo entre as principais alterações está a exigência de inclusão principais assuntos de auditoria, em que os auditores terão de expressar em detalhes a situação encontrada na empresa sob exame. Outra mudança é que o auditor deverá reportar aos conselhos de governança as dificuldades encontradas durante os exames 
e as áreas de risco mais significativas com o intuito de melhor analisar e identificar possíveis erros em relação aos procedimentos adotados pelas companhias (BLB BRASIL, 2016)

Os principais assuntos de auditoria são aqueles que, na avaliação do auditor, foram os de maior importância na auditoria, por exemplo, as áreas que exigiram atenção significativa do auditor no desempenho da auditoria (CONSELHO FEDERAL DE CONTABILIDADE, 2016). Os principais assuntos de auditoria são: assuntos comunicados aos responsáveis pela governança, assuntos que exigiram atenção significativa do auditor na execução da auditoria e principais assuntos de auditoria (KPMG AUDITORES INDEPENDENTES, 2016).

De acordo com o Instituto dos Auditores Independentes do Brasil - Ibracon (2016) os principais afetados são os auditores, os investidores, a administração, os Comitês ou Conselhos, conforme Quadro 1:

\section{Quadro 1 - Quem é afetado com as alterações}

AUDITOR

INVESTIDOR

ADMINISTRAÇÃO
Principal responsável pela aplicação das novas exigências; descrição mais detalhada da sua responsabilidade e julgamentos e maior interação com a alta administração e os responsáveis pela governança

Acesso a informações que não estavam disponiveis antes e considerar como incorporar estas informações na avaliação de empresas ou na comparação entre empresas

Descrição mais detalhada da responsabilidade da administração, incluindo a descrição das responsabilidades pela continuidade operacional

Interagindo mais com o auditor (discutindo o relatório de auditoria antes da sua divulgação) e principal preocupação: certificar-se que o relatório do auditor não divulgue informações sobre a entidade que ainda não estão disponíveis publicamente (informações originais)

Fonte: Instituto dos Auditores Independentes do Brasil (2016).

O novo relatório de auditoria trata-se de um passo respeitável para o amadurecimento da governança corporativa do Brasil, pois busca divulgar o trabalho do auditor independente com uma maior clareza, objetividade e transparência. Além disso, irá ter um maior compromisso da administração com os controles internos, uma vez que tais temas ganharam notoriedade no relatório do auditor (CONTÁBEIS, 2016).

\subsection{Governança Corporativa}

Visando melhores práticas, empresas (privadas e públicas) e demais organizações buscam cada vez mais atender aos interesses de seus diversos usuários - acionistas, gestores, clientes, parceiros e governo, - no que tange adoção de políticas que respaldem a transparência de suas informações, o cumprimento legal e uma postura sustentável.

"A governança corporativa das companhias tem sido objeto de vários estudos nacionais e internacionais e é amplamente reconhecida como um fator essencial para o acesso das empresas ao mercado de capitais" (GARCIA, 2005, p.3). Tem como principal foco a busca por transparência nos negócios, permitindo, assim, o acesso de diversos investidores as informações prestadas pelas organizações (OLIVEIRA et al, 2015).

A confiança dos investidores em relação a obtenção de retorno sobre o investimento realizado "depende de um conjunto de fatores muito mais amplos e subjetivos, relacionados ao ambiente institucional onde a empresa está inserida, em que se destacam a proteção ao investidor, a infraestrutura legal, os direitos de propriedade e a garantia de cumprimento dos contratos" (SILVEIRA, 2004, p. 12).

Nesse sentido, surge a Governança Corporativa na tentativa de superar o conflito de agência e gestores, resultado da separação entre a propriedade e sua gestão, existente em diversas organizações, com o propósito de regulamentar a estrutura administrativa do estabelecimento dos direitos e deveres dos acionistas e da dinâmica da organização dos poderes (GARCIA, 2005).

No geral, a Governança Corporativa busca atender não apenas os interesses da minimização de conflitos entre agente e principal, mas pode ser entendida como uma preocupação estratégica dos empresários que consiste em adquirir confiança de investidores na aquisição de recursos para o financiamento de investimentos futuros. Como também, as empresas sem fins lucrativos precisam prestar contas à comunidade quanto suas ações. E, para atender em ambas as situações, a Governança Corporativa propõe mecanismos que visam harmonizar e compatibilizar a relação entre gestores e acionistas e demais interessados (OLIVEIRA, PEREZ JUNIOR e SILVA, 2013).

Nesse contexto, surge um mecanismo o qual, segundo Srour (2005), poderia garantir uma melhor transparência e, consequentemente, a melhora dos instrumentos de governança, que seria a contratação de auditoria independente e de alta credibilidade. O autor explica ainda que devido a sua reputação, grandes auditorias possuem alto custo em ratificar balanços indevidos, podendo transmitir maior confiabilidade aos investidores externos.

No estudo de Asthana, Balsam e Krishnan (2010) os autores analisaram a associação entre governança corporativa, reputação da firma de auditoria, troca de auditor e reação do preço da ação do cliente de auditoria no mercado norte-americano após os escândalos envolvendo a Enron e sua auditoria Arthur Andersen. Os achados da pesquisa constataram 
que os clientes da Arthur Andersen que tinham melhores práticas de governança corporativa estavam mais propensos a trocar de auditor mais rapidamente após a fraude. Além disso, os autores observaram que as empresas que trocaram de auditor, tiveram retornos anormais positivos durante a janela de três dias do anúncio da troca de auditor.

Sobre a relação entre custos de auditoria e governança corporativa, a pesquisa de Bortolon, Sarlo Neto e Santos (2013) evidenciou uma relação negativa entre essas duas variáveis, sugerindo que, no mercado brasileiro, predomina o efeito risco. Ou seja, melhores práticas de governança reduzem os riscos da auditoria independente permitindo a cobrança de valores menores. Conforme os autores, a maioria dos estudos internacionais apresenta uma relação positiva, a favor do efeito demanda, significando que melhor governança implica em maiores exigências junto ao serviço da auditoria, o que teria como consequência maiores custos de auditoria. Nesse sentido, espera-se que as empresas com melhores práticas de governança corporativa, sejam na ótica dos auditores, negócios de menor risco o que pode levar à menor divulgação de principais assuntos de auditoria nos relatórios.

Kaveski et al. (2016) examinaram a influência dos mecanismos de Governança Corporativa nos gastos com honorários de auditoria e não-auditoria de 88 empresas brasileiras de capital aberto, tendo como resultado que, dentre os mecanismos de Governança Corporativa, as variáveis relacionadas com o tamanho do comitê de auditoria e a reputação da empresa de auditoria independente quando é Big Four, influenciam nos gastos com honorários de auditoria. Tais resultados sugerem que para uma empresa apresentar melhores práticas de governança corporativa, é necessário um maior desembolso para garantir a eficácia de seus mecanismos.

\subsection{Estudos Anteriores}

Por ser uma alteração recente, ainda não há muitas pesquisas realizadas sobre os Principais Assuntos de Auditoria ou a NBC TA 701, no entanto, uma vez que este trabalho visa também avaliar os efeitos dessas mudanças no planejamento e honorários de auditoria, buscou-se também apresentar outros estudos relacionados com o assunto, bem como aqueles que apresentam relações entre os honorários de auditoria e variáveis tais como o nível de governança corporativa, tamanho da empresa, primeira auditoria e outros.

O estudo de Cordos e Fülöp (2015) teve como objetivo investigar se os usuários de relatórios de auditoria concordam com a proposta do IASB de incluir uma nova seção no relatório de auditoria, denominado de principais assuntos de auditoria. Os autores descobriram que vários entrevistados suscitam preocupações legítimas quanto ao processo de implementação dos principais assuntos de auditoria e o seu efeito nos relatórios de auditoria, concluindo que são um conceito importante e que sua introdução e aplicabilidade terão um efeito positivo no processo de relatório de auditoria.

Köhler, Ratzinger-Sakel e Theis (2016) investigaram qual foi o efeito dos principais assuntos de auditoria no relatório do auditor, considerando não apenas os profissionais da área, mas também os profissionais de investimento nos quais foi testado o valor comunicativo de um principal assunto de auditoria. No entanto, os resultados da pesquisa sugerem que a nova seção do relatório não tem valor comunicativo, o que implica que os investidores não profissionais têm dificuldades em processar a informação transmitida com os principais assuntos de auditoria.

O realizado por Lennox, Schmidt, Thompson (2017) analisa se o novo padrão de relatórios de auditoria é informativo para os investidores do Reino Unido, utilizando uma amostra de 488 empresas. Os resultados indicam que as divulgações no relatório do auditor capturam de forma confiável a incerteza nas medidas contábeis, mas não possuem conteúdo de informação incremental, concluindo que os investidores já foram informados sobre a maioria dos riscos antes que eles fossem divulgados pelos auditores nos relatórios de auditoria ampliados.

Assim, com base nos estudos anteriores sobre a implementação dos principais assuntos de auditoria, observa-se inicialmente que essa discussão ocorre predominantemente no âmbito internacional, evidenciando que embora as expectativas sobre sua inclusão sugiram maior transparência e valor informativo, foi constatado que após a adoção inicial, passam a não ser mais comunicativos, pois se trata de informação já divulgada em relatórios anteriores.

Os estudos relacionados com a remuneração dos auditores evidenciam variáveis importantes que determinam os honorários. A pesquisa de Carvalho e Dantas (2015) apresenta que as empresas com melhores práticas de governança corporativa demandam por serviços de auditoria mais caros, e que o tamanho da empresa e o fato de a firma de auditoria ser Big Four apresenta relação positiva com o preço cobrado pelos auditores. Por outro lado, o índice de liquidez corrente e a troca de firma de auditoria apresentaram relação negativa com a remuneração cobrada pelos auditores, e o retorno sobre o patrimônio líquido e o grau de alavancagem não apresentaram relação estatisticamente relevante.

Camargo et al. (2011) analisaram os determinantes do comportamento dos custos com auditoria, apresentando associação positiva com as seguintes variáveis: o tamanho da empresa auditada, o tipo de firma de auditoria contratada, a aderência da empresa auditada a níveis diferenciados de governança corporativa e a complexidade da auditoria realizada. Também apresentou relação negativa entre o tipo de controle (privado ou público), o que denota que auditorias em empresas com controle estatal apresentaram honorários inferiores àquelas com controle privado.

Kaveski e Cunha (2016) constataram que o tamanho e a alavancagem são fatores determinantes para explicar os honorários de auditoria independente, assim, quanto maior for o tamanho da empresa e menor a sua alavancagem, maiores serão os honorários dos auditores independentes das empresas do Novo Mercado.

Nesse contexto, não há um consenso quanto ao que se espera dos auditores sobre a remuneração da auditoria após adoção da NBC TA 701. Por um lado, o custo estaria relacionado com complexidade da auditoria realizada conforme 
mencionado por Kaveski e Cunha (2016), considerando ainda a necessidade de elaborar um relatório mais extenso e informativo que poderia expor a empresa auditada e auditores. Por outro lado, a identificação dos riscos de auditoria já era realizada, passando agora a ser divulgado no relatório, o que não se esperaria um aumento significativo dos honorários.

\section{METODOLOGIA DA PESQUISA}

A metodologia científica compreende o conjunto de etapas ordenadamente dispostas a serem executadas na investigação de um fenômeno. Além de descritiva, a pesquisa também é classificada como exploratória, tendo em vista a abordagem de um tema recente e pouco estudado. Mesmo no contexto internacional, o qual a norma foi discutida pelo IFAC e aplicada aos relatórios financeiros no exercício de 2015, a temática ainda é pouco explorada, sendo evidenciadas menos de cinco publicações sobre o assunto nas plataformas internacionais de periódicos acadêmicos.

Com relação aos procedimentos da pesquisa, este estudo utiliza a pesquisa bibliográfica e de campo (survey). O método de pesquisa de campo foi abordado por meio da aplicação de questionário, que é definido como "uma investigação empírica realizada no local onde ocorre ou ocorreu um fenômeno ou que dispõe de elementos para explicá-lo" (VERGARA, 2007, p. 47). A utilização desse tipo de pesquisa é importante, pois traz informações que podem ser úteis no futuro, podendo se realizar posteriormente estudos mais específicos.

Sobre a abordagem do problema, esta pesquisa possui natureza qualitativa, pois buscou-se analisar a opinião dos auditores quanto às mudanças do relatório mediante a NBC TA 701, sem que fossem aplicadas estatísticas multivariadas. Os dados foram apresentados por meio de tabelas e gráficos que auxiliaram no entendimento da percepção dos auditores e permitiram conclusões acerca do tema.

\subsection{Coleta e Tratamento dos Dados}

No que diz respeito aos instrumentos de coleta de dados, visando o objetivo da pesquisa bem como seu método que é o de pesquisa de campo, descrito anteriormente, foram utilizados questionários. Para que se tenha acesso a percepção de certa população é necessário o questionamento direto a mesma.

O questionário foi elaborado com base nas orientações da NBC TA 701 e estudos anteriores relacionados com as expectativas de sua implementação. Além das questões sociodemográficas usadas para caracterizar a amostra, foram colocadas duas questões de escala Likert, sendo: i) quatro níveis de concordância para quatro itens relacionados com a definição e objetivos dos principais assuntos de auditoria e, ii) quatro níveis de importância para sete itens relacionados com a estrutura do novo relatório. Além dessas, foram aplicadas mais duas questões abertas visando mais profundidade no conhecimento adquirido

O questionário foi aplicado inicialmente aos 330 auditores independentes de empresas brasileiras não financeiras de capital aberto, cujos endereços eletrônicos estavam disponíveis nos formulários de referência. Ainda, para obtenção das respostas, o questionário, que foi elaborado utilizando a ferramenta Google Docs, foi disponibilizado aos auditores por intermédio do IBRACON que encaminhou também a pesquisa aos seus associados, durante o mês de novembro de 2016. Por se tratar de formulário eletrônico com itens de resposta obrigatória, nenhum questionário foi excluído da amostra. Ao todo, 63 auditores se propuseram a responder o instrumento de coleta de dados, o qual passou ainda por um pré-teste com dois profissionais que indicaram possíveis questões de interpretação ambígua, as quais foram posteriormente corrigidas. Buscaram-se auditores com maior tempo de experiência ou com cargos chave nas firmas para que se pudessem ser coletadas as percepções de auditores experientes, que atuam também no planejamento de auditoria e elaboração do relatório.

Após coletados os dados, os mesmos foram tabulados em planilha no Excel e elaboradas tabelas e gráficos para apresentação e análise dos resultados, buscando alcançar os objetivos propostos no estudo.

\section{ANÁLISE DOS RESULTADOS}

Esta seção visa apresentar os resultados da pesquisa para alcançar o objetivo geral proposto, o qual é analisar quais as expectativas dos auditores independentes quanto ao novo relatório de auditoria independente (NRA) e os efeitos no planejamento e honorários deste serviço, com base no questionário aplicado a 63 auditores independentes. A Tabela 1 mostra a distribuição o perfil dos auditores avaliados, pela pesquisa online de participação voluntária.

Tabela 1 - Perfil Auditores

\begin{tabular}{cccc}
\hline Gênero & Frequência & Frequência (\%) \\
\hline Masculino & 51 & $81,0 \%$ \\
Feminino & 12 & $19,0 \%$ \\
TOTAL & $\mathbf{6 3}$ & $\mathbf{1 0 0 , 0} \%$ \\
\hline
\end{tabular}




\begin{tabular}{|c|c|c|}
\hline Faixa etária & Frequência & Frequência (\%) \\
\hline Até 20 anos & 0 & $0,0 \%$ \\
\hline Entre 20 e 25 anos & 4 & $6,3 \%$ \\
\hline Entre 25 e 30 anos & 4 & $6,3 \%$ \\
\hline Entre 30 e 35 anos & 3 & $4,8 \%$ \\
\hline Acima de 35 anos & 52 & $82,5 \%$ \\
\hline TOTAL & 63 & $100,0 \%$ \\
\hline Tempo de experiência com auditoria independente & Frequência & Frequência (\%) \\
\hline Até 3 anos & 5 & $7,9 \%$ \\
\hline Entre 3 e 5 anos & 7 & $11,1 \%$ \\
\hline Entre 5 e 7 anos & 2 & $3,2 \%$ \\
\hline Entre 7 e 9 anos & 2 & $3,2 \%$ \\
\hline Acima de 9 anos & 47 & $74,6 \%$ \\
\hline TOTAL & 63 & $100,0 \%$ \\
\hline $\begin{array}{l}\text { Possui CNAI (Cadastro Nacional de Auditor } \\
\text { Independente) }\end{array}$ & Frequência & Frequência (\%) \\
\hline Sim & 45 & $71,4 \%$ \\
\hline Não & 18 & $28,6 \%$ \\
\hline TOTAL & 63 & $100,0 \%$ \\
\hline Trabalha em Big Four & Frequência & Frequência (\%) \\
\hline Sim & 24 & $38,1 \%$ \\
\hline Não & 39 & $61,9 \%$ \\
\hline TOTAL & 63 & $100 \%$ \\
\hline
\end{tabular}

Fonte: Resultados da pesquisa (2016)

A Tabela 1 mostra o perfil dos auditores da amostra, que a maior parte dos auditores da amostra do sexo masculino (81\%), sendo que a maioria dos auditores (71,4\%) é cadastrada no CNAI (Cadastro Nacional de Auditor Independente). Cerca de $80 \%$ dos auditores tem acima de 35 anos de idade e $75 \%$ com mais de 9 anos de experiência em auditoria.

A Tabela 2 mostra a opinião dos auditores referente aos níveis de governança corporativa. Percebe-se que $54 \%$ dos auditores avaliados acreditam que não há nenhuma relação entre a quantidade de principais assuntos de auditoria a serem relatados no relatório e o nível de Governança Corporativa, enquanto que 36\% entendem que empresas com melhores práticas de governança tendem a ter menor risco do negócio, levando à redução na divulgação de principais assuntos de auditoria. Já 9,5\% dos respondentes, todos com mais de 9 anos de experiência de auditoria responderam abertamente a questões, relevando que os principais assuntos de auditoria dependem efetivamente dos controles internos. Além disso, outro auditor relatou que "rigorosamente, as governanças corporativas têm sido "orientadas" pelos executivos na medida de suas necessidades. As GC têm demonstrado ser instrumentos pouco eficazes nos seus propósitos (sic)" e por fim, outro profissional descreveu que "diversos estudos provaram que alta governança corporativa não garante ausência inconformidades contábeis, financeiras ou operacionais (sic).” 
Tabela 2 - Opinião dos Auditores sobre os Níveis de Governança Corporativa

\begin{tabular}{ccc}
\hline $\begin{array}{c}\text { Você acha que as empresas com melhores niveis de } \\
\text { Governança Corporativa terão menos Principais Assuntos } \\
\text { de Auditoria abordados no relatório de auditoria } \\
\text { independente? }\end{array}$ & Frequência & Frequência (\%) \\
\hline Sim, pois têm menos riscos de negócio. & 23 & $36,5 \%$ \\
Não vejo nenhuma correlação entre essas variáveis. & 34 & $54,0 \%$ \\
Outro & 6 & $9,5 \%$ \\
\hline
\end{tabular}

Fonte: Resultados da pesquisa (2016)

A Tabela 3 mostra o resultado com base na escala de concordância de 1 a 4 , sendo 4 o maior nível de concordância atribuído a comunicação dos principais assuntos de auditoria, conforme a NBC TA 701 na percepção dos auditores independentes:

Tabela 3 - Comunicação dos principais assuntos de auditoria

\begin{tabular}{|c|c|c|}
\hline & ITEM & MÉDIA \\
\hline 1 & $\begin{array}{l}\text { A comunicação dos principais assuntos de auditoria visa tornar o relatório de auditoria mais informativo, ao } \\
\text { dar maior transparência sobre a auditoria realizada }\end{array}$ & 3,54 \\
\hline 2 & $\begin{array}{l}\text { A comunicação dos principais assuntos de auditoria fornece informações adicionais aos usuários previstos } \\
\text { das demonstrações contábeis, para auxiliá-los a entender os assuntos que, segundo o julgamento profissional } \\
\text { do auditor, foram os de maior importância na auditoria das demonstrações contábeis do período corrente. }\end{array}$ & 3,54 \\
\hline 3 & $\begin{array}{c}\text { A comunicação dos principais assuntos de auditoria também pode ajudar os usuários previstos das } \\
\text { demonstrações contábeis a entender a entidade e as áreas que envolveram julgamento significativo da } \\
\text { administração nas demonstrações contábeis auditadas }\end{array}$ & 3,33 \\
\hline 4 & $\begin{array}{c}\text { A comunicação dos principais assuntos de auditoria no relatório do auditor também pode fornecer aos } \\
\text { usuários previstos das demonstrações contábeis uma base para obtenção de informações adicionais com a } \\
\text { administração e com os responsáveis pela governança sobre determinados assuntos relacionados à entidade, } \\
\text { às demonstrações contábeis auditadas ou à auditoria realizada. }\end{array}$ & 3,22 \\
\hline
\end{tabular}

Fonte: Resultados da pesquisa (2016)

Com base nos resultados da Tabela 3, observa-se que de forma geral, os auditores concordam com as comunicações dos principais assuntos de auditoria, que é uma novidade advinda da NBC TA 701. A média dos itens analisados é 3,41 , indicando que os auditores ainda não concordam totalmente, mas entendem que essas comunicações permitem maior transparência e relevância do relatório do auditor independente, fornecendo informações adicionais para melhor entendimento da condução da auditoria e dos riscos identificados. Tal resultado é contrário ao esperado por Köhler, Ratzinger-Sakel e Theis (2016) e Lennox, Schmidt, Thompson (2017) que sugerem que a nova seção do relatório não tem valor comunicativo e que as divulgações no relatório do auditor não possuem conteúdo de informação incremental. Os resultados também podem ser visualizados no Gráfico 1. 
Gráfico 1 - Comunicação dos principais assuntos de auditoria

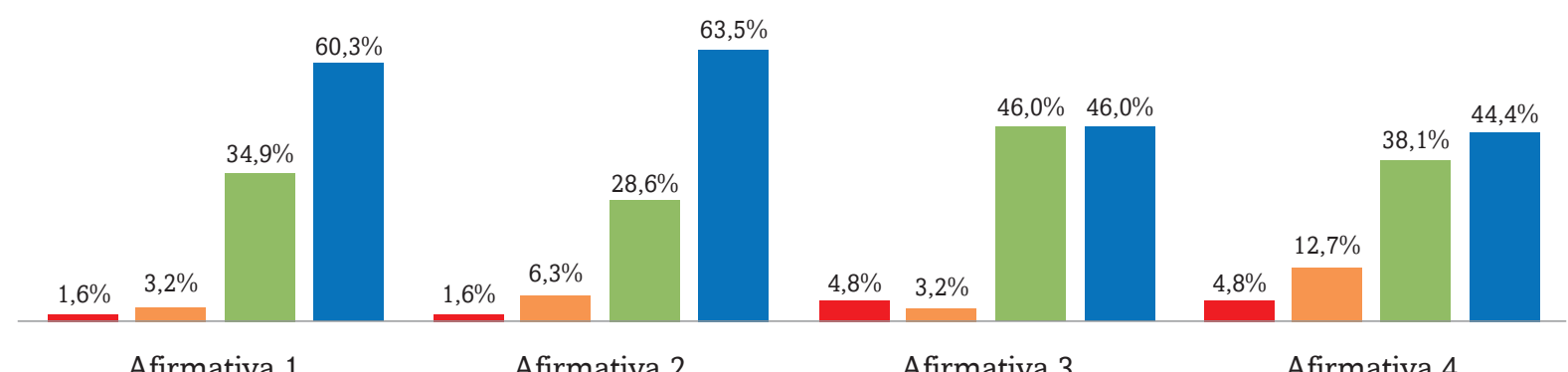

Afirmativa 1

Afirmativa 2

Afirmativa 3

Afirmativa 4

Discordo totalmente

- Discordo mais do que concordo

- Concordo mais do que discordo $\quad$ Concordo totalmente

Fonte: Resultados da pesquisa (2016)

A Tabela 4 apresenta os resultados referentes ao nível de importância dado pelos auditores em uma escala de 1 a 4 , sendo 4 muito importante, quanto às divulgações no relatório de auditoria independente, tais como as responsabilidades da administração e da auditoria, conteúdo dos principais assuntos de auditoria e Incerteza relevante relacionada com a continuidade operacional em parágrafo específico.

Tabela 4 - Divulgação dos itens abaixo no relatório de auditoria independente

\begin{tabular}{|c|c|c|}
\hline & ITEM & MÉDIA \\
\hline 1 & Áreas avaliadas como de maior risco de distorção relevante ou riscos significativos identificados. & 3,59 \\
\hline 2 & $\begin{array}{l}\text { Julgamentos significativos do auditor relativos às áreas das demonstrações contábeis que também } \\
\text { envolveram julgamento significativo por parte da administração, inclusive estimativas contábeis } \\
\text { identificadas que apresentam alto grau de incerteza na estimativa. }\end{array}$ & 3,59 \\
\hline 3 & Efeito sobre a auditoria de fatos ou transações significativas ocorridas durante o período. & 3,19 \\
\hline 4 & $\begin{array}{c}\text { Níveis de materialidade considerados na elaboração, apresentação e auditoria das } \\
\text { demonstrações contábeis. }\end{array}$ & 2,84 \\
\hline 5 & $\begin{array}{l}\text { Divulgação separada sob o título "Incerteza relevante relacionada com a continuidade operacional", } \\
\text { quando existe incerteza relevante que pode levantar dúvida significativa quanto à capacidade de } \\
\text { continuidade operacional da entidade e este fato é divulgado adequadamente no relatório da empresa. }\end{array}$ & 3,59 \\
\hline 6 & $\begin{array}{l}\text { Responsabilidade da auditoria independente quanto à identificação e avaliação dos riscos de distorção } \\
\text { relevante nas demonstrações contábeis, entendimento dos controles internos relevantes para a } \\
\text { auditoria, adequação das políticas contábeis utilizadas e a razoabilidade das estimativas e adequação } \\
\text { do uso da base contábil de continuidade operacional. }\end{array}$ & 3,46 \\
\hline 7 & $\begin{array}{l}\text { Responsabilidade da administração quanto à elaboração das demonstrações contábeis, pelos } \\
\text { controles internos que ela determinou como necessários e avaliação da capacidade de a Companhia } \\
\text { continuar operando. }\end{array}$ & 3,63 \\
\hline
\end{tabular}

Fonte: Resultados da pesquisa (2016)

Com base na Tabela 4, é possível verificar que os auditores independentes consideram importantes as divulgações abordadas na nova estrutura do relatório de auditoria independente, com uma média geral de 3,41 no nível de importância dado a esses elementos. Destaca-se o item 4 que trata sobre a apresentação dos níveis de materialidade considerados na elaboração, apresentação e auditoria das demonstrações contábeis, no qual obteve menor grau de importância com média 2,84. Os níveis de materialidade não são exigidos como divulgação pela norma NBC TA 701, no entanto, tem sido divulgado nos relatórios de auditoria na experiência do Reino Unido e Irlanda, conforme Financial Reporting Council (2016). Os resultados desta análise também podem ser evidenciados por meio do Gráfico 2. 
Gráfico 2 - O grau de importância da divulgação dos itens

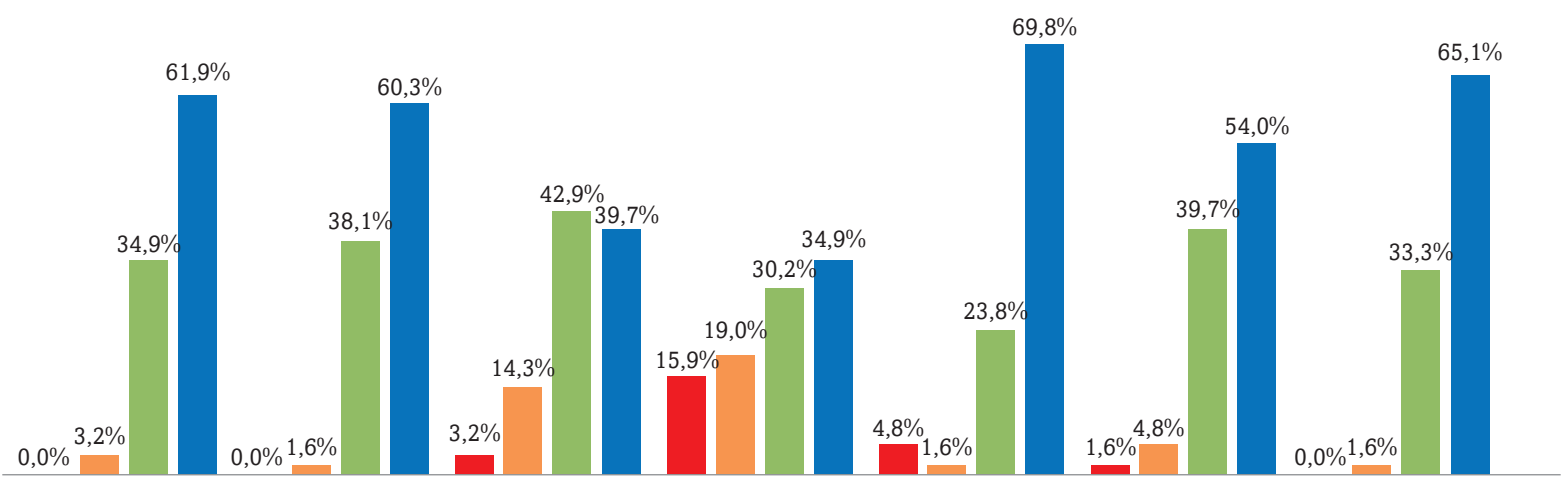

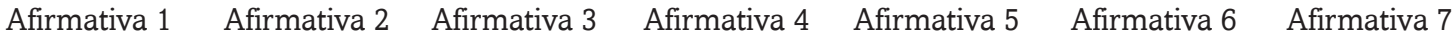

Nada Importante $\square$ Pouco Importante $\square$ Importante $\square$ Muito Importante

Fonte: Resultados da pesquisa (2016)

A Tabela 5 mostra a distribuição de frequências da opinião dos auditores em relação à influência de cinco variáveis na composição dos honorários de auditoria, quais sejam: nível de governança corporativa, complexidade dos negócios, primeira firma de auditoria, tamanho da empresa e vínculo com agências reguladoras.

Tabela 5 - Influência das variáveis abaixo na composição dos honorários de auditoria independente

\begin{tabular}{cccc}
\hline & $\begin{array}{c}\text { Menores } \\
\text { honorários }\end{array}$ & Indiferente & $\begin{array}{c}\text { Maiores } \\
\text { honorários }\end{array}$ \\
\hline Alto nível de Governança Corporativa & $50,8 \%$ & $38,1 \%$ & $11,1 \%$ \\
Alta complexidade dos negócios & $1,6 \%$ & $4,8 \%$ & $93,7 \%$ \\
Primeira auditoria da firma na empresa & $4,8 \%$ & $19,0 \%$ & $76,2 \%$ \\
Empresa de grande porte & $7,9 \%$ & $31,7 \%$ & $60,3 \%$ \\
Empresa que atua em setores vinculados às agências reguladoras & $6,3 \%$ & $19,0 \%$ & $74,6 \%$ \\
\hline
\end{tabular}

Fonte: Resultados da pesquisa (2016)

Os resultados da Tabela 5 mostram a opinião dos auditores quanto à influência das variáveis abordadas nesta pesquisa na composição dos honorários de auditoria independente. Desta forma, é possível verificar que parte dos auditores $(50,8 \%)$ entende que um nível diferenciado de Governança Corporativa tende a reduzir os honorários de auditoria, possivelmente pela redução dos riscos associados à gestão do negócio. Essa percepção corrobora com Bortolon, Sarlo Neto e Santos (2013) e é contrária aos estudos de Carvalho e Dantas (2015) e Camargo et al (2011).

Por outro lado, a maioria $(93,7 \%)$ entende que maior complexidade do negócio leva a maior volume desses honorários, concordando com Camargo et al (2011), e Prasad e Chand (2017) que acreditam que as mudanças no relatório aumentarão os custos de auditoria e, dessa forma, a responsabilidade legal dos auditores. Assim também é a opinião da maioria de 60,3\% quanto ao maior porte da empresa auditada, o que também concorda com os achados de Camargo et al (2011), Carvalho e Dantas (2015) e Kaveski e Cunha (2016). Quanto a uma primeira auditoria realizada, 76,2\% entendem que isso levaria a honorários mais elevados, pois seriam necessários mais procedimentos e testes, no entanto, essa variável não foi significativa na pesquisa quantitativa. Por fim, os auditores também entendem que uma empresa que atua em setores vinculados às agências reguladoras tende a arcar com maiores honorários de auditoria, cuja complexidade e compliance do negócio aumentam, mas a pesquisa quantitativa não encontrou correção com essa variável. Os resultados dessas variáveis também podem ser visualizados no Gráfico 3. 
Gráfico 3 - Influência das variáveis na composição dos honorários de auditoria

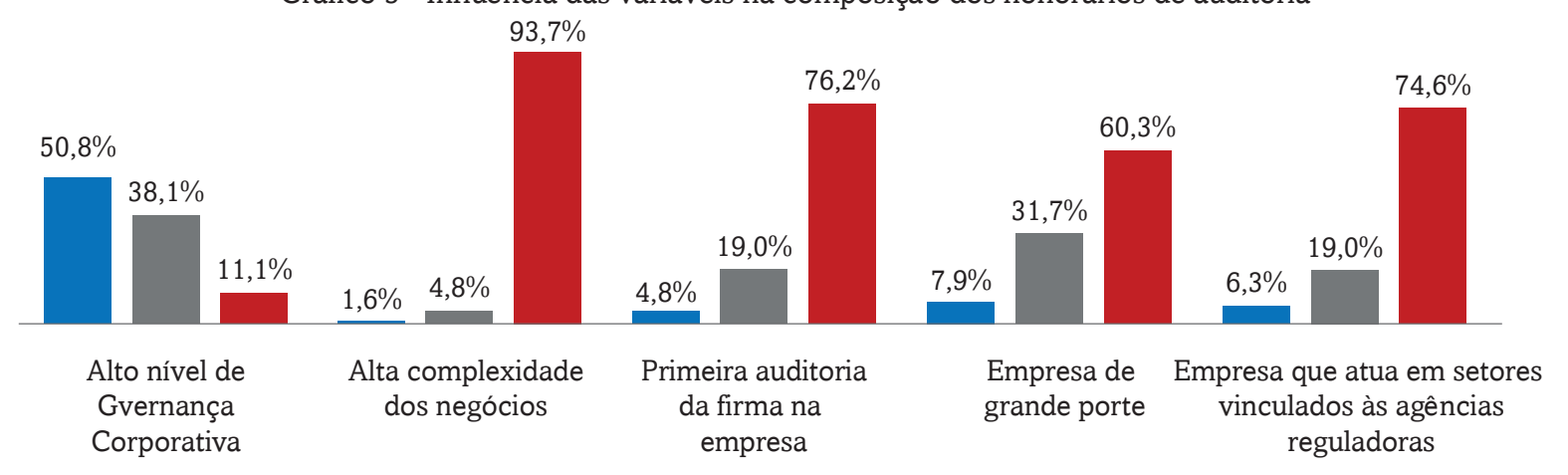

Menores honorários $\quad$ Indiferente Maiores honorários

Fonte: Resultados da pesquisa (2016)

Foi questionado aos auditores sobre quais efeitos teriam nos honorários da auditoria independente em decorrência das mudanças das normas técnicas de auditoria, em especial a inclusão da NBC TA 701 - Principais Assuntos de Auditoria. Desta forma, verifica-se que há divisão de opiniões entre os respondentes da amostra, enquanto que alguns entendem que essas mudanças ocasionarão aumento de honorários, outros entendem que não há relação. Um dos respondentes diz: "Julgo que terá aumento de horas para melhor adequação desta norma e consequente aumento de honorários."

A princípio, o efeito será diretamente na empresa de auditoria (para o ano corrente), uma vez que será demandada mais horas de sócios na participação, discussão e elaboração do relatório do auditor. Se a empresa de auditoria conseguir repassar estes custos para o cliente, entendo que os honorários cobrados serão maiores. Adicionalmente, serão gastas mais horas de gerente e sênior para a discussão com a administração (diretoria e conselho) sobre o novo relatório e os principais assuntos. Entendo que para o próximo ano fiscal o impacto será maior do que para o ano corrente, uma vez que o relatório se tornará obrigatório para todos os clientes, e não apenas para as empresas CVM (AUDITOR 5).

Categorizando as respostas e quantificando-as, ficou evidente que $60 \%$ da amostra entende que não terá aumento de honorários, corroborando com o levantamento do Financial Reporting Council (2016) na experiência de 2014 e 2015 no Reino Unido e Irlanda que não constaram aumento significativo dos honorários em decorrência da mudança da estrutura do relatório de auditoria. A seguir consta a opinião de um auditor sobre a expectativa de não aumentar honorários em decorrência da norma NBC TA 701:

Uma empresa de auditoria séria, que calcula seus honorários considerando o esforço necessário para auditar a empresa tendo em vista os riscos de negócio, nível de controles internos e demais itens, não deveria ter uma mudança substancial de abordagem por conta dessa mudança e, portanto, dos seus honorários. Portanto, os efeitos nos seus honorários deveriam ser, apenas, de preparar um parecer mais robusto, com o envolvimento de outros revisores, já que antes o parecer era padronizado e não exigia tal esforço. Se alguma empresa aumentar substancialmente os honorários por conta dessa mudança é porque não estava executando seus trabalhos de acordo com as normas de auditoria internacionais (AUDITOR 14).

Por fim, porém não menos importante, questionou-se aos profissionais quais efeitos teria no planejamento da auditoria independente em decorrência das mudanças das normas técnicas de auditoria, em especial a inclusão da NBC TA 701 - Principais Assuntos de Auditoria. Categorizando as respostas e quantificando-as, foi possível evidenciar que 65\% dos auditores entendem que isso impactará no planejamento de auditoria, necessitando de mais horas de planejamento, maior responsabilidade, mais horas de discussão com a governança levando a maior participação de sócios da firma de auditoria. Por outro lado, dentre os $35 \%$ de auditores que entendem que não vai mudar significativamente no planejamento de auditoria, esses profissionais entendem que a identificação de riscos do cliente e os efeitos disso na execução de auditoria já eram procedimentos realizados, e que a divulgação disso no relatório de auditoria não acarretaria em grandes efeitos no planejamento da auditoria.

Não deveria ter efeito relevante no planejamento, pois esses assuntos já deveriam fazer parte da avaliação do auditor para definir sua abordagem e executar seus testes. O que muda é, de fato, a divulgação sobre o julgamento e conclusões do auditor no seu relatório de auditoria (AUDITOR 15).

Comunicação mais eficiente e antecipada sobre os PAAs com os órgãos de governança da empresa auditada, o que requer envolvimento de profissionais mais seniores nas etapas prévias do trabalho, em especial quando do planejamento (AUDITOR 48).

\section{CONSIDERAÇÕES FINAIS}

O presente estudo teve como objetivo analisar quais as expectativas dos auditores independentes quanto ao novo relatório de auditoria independente (NRA) e os efeitos no planejamento e honorários do serviço. Para alcançar o objetivo 
foi aplicado um questionário para 63 auditores independentes com maior tempo de experiência no mercado e com cargos em nível de planejamento de auditoria.

Os resultados apontam que os auditores concordam em sua maioria quanto à comunicação dos principais assuntos de auditoria (PAAs), bem como entendem ser importante a divulgação de elementos no relatório de auditoria independente, tais como as responsabilidades da administração e da auditoria, conteúdo dos principais assuntos de auditoria e Incerteza relevante relacionada com a continuidade operacional em parágrafo específico, conforme mudanças nas NBC TAs 570, 700, 701 e 705.

Os profissionais ainda relataram sobre o planejamento e honorários de auditoria, indicando provável aumento quando há alta complexidade dos negócios, maior porte do cliente, quando é realizada a primeira auditoria e quando o cliente é vinculado a agências reguladoras. Por outro lado, entendem que uma empresa com melhores práticas de governança provavelmente terá menores custos com remuneração dos auditores, pois há previsão de menores riscos do negócio. Foi observado também que essa relação não há total consenso entre as pesquisas anteriores, o que merece novos estudos que direcionem a uma resposta melhor definida.

Quanto aos efeitos dos principais assuntos de auditoria no planejamento e honorários, verificou-se que a percepção geral é que a maioria entende que não haverá efeitos relevantes nos honorários de auditoria. Por outro lado, a maioria também entende que terão efeitos no planejamento de auditoria devido principalmente a participação de auditores seniores ou sócios nas discussões com a empresa auditada. Há também o entendimento de que a identificação de riscos do cliente e os efeitos disso na execução de auditoria já eram procedimentos realizados, e que a divulgação disso no relatório de auditoria não acarretaria em grandes efeitos no planejamento da auditoria.

Conclui-se que a adoção da NBC TA 701 nos relatórios de auditoria independente terá inicialmente como efeito prático uma mudança no planejamento desse serviço em decorrência da necessidade de identificar os principais assuntos de auditoria e divulgá-los no relatório, no entanto, isso não acarretaria em aumento significativo dos honorários de auditoria. Por outro lado, por trata-se de uma tarefa já realizada nas auditorias, a divulgação dos principais assuntos de auditoria também não terá ganho informativo, principalmente após a adoção inicial. Portanto, espera-se que futuramente novas alterações na estrutura do relatório serão demandadas para que o mesmo não se torne padronizado entre as firmas.

Por fim, sugerem-se para pesquisas futuras a análise dos relatórios de auditoria referentes aos exercícios posteriores à 2016 em que já foram publicados os relatórios de auditoria com a nova estrutura, no intuito de verificar a quantidade de principais assuntos de auditoria, bem como o teor dessas informações tais como os riscos identificados e os efeitos destes na realização da auditoria. Além disso, é necessário analisar os honorários de auditoria para certificar se houve efeitos marginais na composição da remuneração dos auditores independentes. Tais pesquisas serão importantes para confrontar com as expectativas dos auditores relatadas neste estudo, avaliando sua capacidade de compreensão às mudanças normativas e experiências profissionais nesta área.

\section{REFERÊNCIAS}

ACADEMIA PAULISTA DE CONTABILIDADE. O Novo Relatório do Auditor se aplica às Demonstrações Contábeis de 2016. Disponível em: <http://www.apcsp.org.br/capa.asp?idnoticia=73> Acesso em: 18 de nov. 2016.

Asthana, Sharad C.; Balsam, Steven; Krishnan, Jagan. Corporate Governance, Audit Firm Reputation, Auditor Switches, and Client Stock Price Reactions: The Andersen Experience. International Journal of Auditing. 14: 274-293, 2010.

ATTIE, Willian. Auditoria: conceitos e aplicações. 6 ed. São Paulo: Atlas, 2011.

BACKOF, Ann; BOWLIN, Kendall; GOODSON, Brian. The impact of proposed changes to the content of the audit report on jurors' assessments of auditor negligence. (January, 2017). Available at: <https://papers.ssrn.com/sol3/papers.cfm?abstract_id $=2446057>$. Acesso em jan. 2018.

BLB BRASIL. Relatório do auditor. Disponível em: <http://www.blbbrasil.com.br/artigos/relatorio-do-auditor-mudancas/> Acesso em: 18 de nov. 2016.

BORTOLON, Patricia Maria; SARLO NETO, Alfredo; SANTOS, Thaís Barreto. Custos de Auditoria e Governança Corporativa. Disponível em: <http://search.proquest.com/openview/5a93d3ae2de9176b3b81cd8510690035/1?pq-origsite=gscholar> Acesso em: 12 de nov. 2016.

CAMARGO, Raphael Vinicius Weigert; PEPINELLI, Rita de Cássia C.; DUTRA, Marcelo Haendchen; ALBERTON, Luiz. Fatores determinantes do comportamento dos custos com auditoria independente nas empresas negociadas na BM\&FBOVESPA. Disponível em: <https://anaiscbc.emnuvens.com.br/anais/article/view/461/461>. Congresso Brasileiro de Custos. Anais... 2011. Acesso em: 23 de nov. 2016.

CARVALHO, Paulo Roberto Matos; DANTAS, José Alves. Relação entre a remuneração dos auditores e a estrutura de governança corporativa das companhias auditadas. $5^{\circ}$ Prêmio Transparência Universitária Ibracon, 2015.

CONTÁBEIS. O novo relatório de auditoria. Disponível em: <http://www.contabeis.com.br/artigos/3297/o-novo-relatorio-de-audito$\mathrm{ria} />$ Acesso em: 18 de nov. 2016.

CONSELHO FEDERAL DE CONTABILIDADE. Normas do novo relatório do auditor independente são publicadas pelo CFC. Disponível em: <http://cfc.org.br/noticias/normas-do-novo-relatorio-do-auditor-independente-saopublicadas-pelo-cfc/> Acesso em 29 de out.de 2016. 
CONSELHO FEDERAL DE CONTABILIDADE. Norma NBC TA 701 - Comunicação dos Principais Assuntos de Auditoria no Relatório do Auditor Independente. Brasília, 04 de julho de 2016.

CORDOŞ, George-Silviu; FÜLÖP, Melinda-Timea. Understanding audit reporting changes: introduction of Key Audit Matters. Accounting and Management Information Systems. Vol. 14, No. 1, p. 128-152, 2015.

FINANCIAL REPORTING COUNCIL. Extended auditor's reports - a further review of experience. Janeiro, 2016.

GARCIA, Arthur Felix. Governança corporativa. 2005. 41 f. Monografia. Instituto de Economia. Universidade Federal do Rio de Janeiro, Rio de Janeiro, 2005.

KAVESKI, Itzhak David Simão; CUNHA, Paulo Roberto da. Fatores Determinantes dos Honorários da Auditoria das Empresas Listadas no Novo Mercado da BM\&FBOVESPA. Contabilidade, Gestão e Governança. Brasília. v. 19. n. 1. p. 49-63. jan./abr. 2016.

KAVESKI, Itzhak David Simão; DEGENHART, Larissa; FERNANDES, Marta Souza; FARIA, Luiz Fernando Cândido de; MANUEL JUNIOR, Marcos Moreira Manuel. Qualidade da governança corporativa, honorários de auditoria e não-auditoria das empresas brasileiras de capital aberto do índice de ações com governança corporativa diferenciada (IGCX). GEECont, v.3, n.1, Floriano-PI, Jan-Jun. 2016.

KÖHLER, Annette G.; RATZINGER-SAKEL, Nicole V. S.; THEIS, Jochen C. The Effects of Key Audit Matters on the Auditor's Report's Communicative Value: Experimental Evidence from Investment Professionals and Non-professional Investors. (August, 2016). Available at SSRN: <https://papers.ssrn.com/sol3/papers.cfm?abstract_id=2934682>. Acesso em dez. 2017.

KPMG. Novo relatório do auditor. Disponível em: <https://home.kpmg.com/br/pt/home/services/audit/novo-relatorio-auditor. html>. Acesso em nov. 2016.

LENNOX, Clive S; SCHMIDT, Jaime J; e THOMPSON, Anne. Is the Expanded Model of Audit Reporting Informative to Investors? Evidence from the UK (February 8, 2017). Available at SSRN: <https://papers.ssrn.com/sol3/papers.cfm?abstract_id=2619785>.

LONGO, Claudio Gonçalo. Manual de auditoria e revisão de demonstrações financeiras. 2 ed. São Paulo: Atlas, 2011.

MANOEL, Jorge; QUEL, Luiz Felipe. Innovation in the international standards for the new independent audit report. Journal on Innovation and Sustainability, volume 8, número $1-2017$.

OLIVEIRA, Daniel; SILVA, Maurício P. da; LIMA, Tábata A.; SOUZA, Monica M. M. Um estudo exploratório da gestão de pessoas na integração e disseminação da governança corporativa. AugustoGuzzo Revista Acadêmica, São Paulo. v.2. n.16. jul/dez. 2015. Disponível em: <http://fics.edu.br/index.php/augusto_guzzo/article/view/301/Augusto\%20\%20\%20Guzzo\%20Revista\%20Acad\%C3\%AAmica> Acesso em: 23 abr. 2016.

OLIVEIRA, Luís Martins de; PEREZ Junior José Hernandez, SILVA, Carlos Alberto dos Santos. Controladoria estratégica. São Paulo: Atlas, 2013.

PRASAD, Pranil; CHAND, Parmod. The Changing Face of the Auditor's Report: Implications for Suppliers and Users of Financial Statements. Australian Accounting Review. Vol. 27, Issue 4, 2017.

SANTOS, Naiara Leite dos; MARTINS, Caroline Miriã Fontes; MARTINS, Pablo Luiz; SANTOS NETA, Maria do Carmo; CHAIN, Caio Peixoto. Avaliação dos analistas de mercado sobre a relevância dos trabalhos dos auditores independentes na análise financeira das sociedades anônimas (S.A.) de capital aberto. Revista Eletrônica de Administração (Online) ISSN: 1679-9127. v. 12. n.1. ed. 22. jan-jun 2013.

SILVA, Franklin Carlos Cruz Da; SILVA, Maria Valesca Damásio De Carvalho. O Que Não Foi Revelado? um estudo sobre a qualidade dos relatórios de auditoria em relação à exposição das empresas a riscos com instrumentos financeiros derivativos. In: XIV Congresso USP Contabilidade e Controladoria. Anais... 2014.

SILVEIRA, Alexandre Di Micelida. Governança corporativa e estrutura de propriedade: determinantes e relação com o desempenho das empresas no Brasil. 2004. 254 f. Tese. Faculdade de Economia, Administração e Contabilidade. Universidade de São Paulo, São Paulo, 2004. Disponível em: <http://mrm.comunique-se.com.br/arq/132/arq_132_13600.pdf> Acesso em: 01 de mai. 2016.

SROUR, Gabriel. Práticas Diferenciadas de Governança Corporativa: Um Estudo sobre a Conduta e a Performance das Firmas Brasileiras. RBE Rio de Janeiro 59(4):635-674 OUT/DEZ 2005.

VERGARA, Sylvia Constant. Projetos e relatórios de pesquisa em administração. São Paulo: Atlas, 2011, 56 p. 